\title{
Numerical simulation and experimental validation on fabrication of nickel-based superalloy Kagome lattice sandwich structures
}

\author{
Yan-peng Wei ${ }^{1,2}$, *Bo Yu ${ }^{1,2}$, Quan-zhan Yang ${ }^{1,2}$, Peng Gao ${ }^{1,2}$, Jian Shi ${ }^{1,2}$, Zhi-quan Miao ${ }^{1,2}$, Jing-chang Cheng ${ }^{1,2}$, and \\ Xun Sun ${ }^{1,2}$ \\ 1. Shenyang Research Institute of Foundry Co. Ltd., Shenyang 110022, China \\ 2. State Key Laboratory of Light Alloy Casting Technology for High-end Equipment, Shenyang 110022, China
}

\begin{abstract}
Nickel-based superalloy lattice sandwich structures present higher stiffness, higher strength and higher temperature resistance in comparison with other metals. In this study, the Kagome unit was adopted to design the lattice sandwich structure and ProCAST software was used to simulate the filling and solidification processes of the nickel-based superalloy. Grain morphology and sizes of the nickel-based superalloy lattice sandwich structures were simulated by using of cellular automaton coupled with finite element model (CAFE), and indirect additive manufacture combining with investment casting were carried out to fabricate the nickel-based superalloy lattice sandwich structures. The calculated grain morphology and sizes are in good agreement with the experimental results. The grains are mainly equiaxed with an average size of about $500 \mu \mathrm{m}$. The simulated results also show that the superheat of melting and the mold preheated temperature have significant influence on the grain size of the Kagome lattice sandwich structures, lower superheat of melting and mold preheated temperatures are encouraged to obtain the fine grains while assuring the integrity of the Kagome lattice sandwich structures for industrial application.
\end{abstract}

Key words: Kagome unit cell; lattice structure; fabrication; grain morphology and size; CAFE model

CLC numbers: TG146.1 5 Document code: A Article ID: 1672-6421(2020)01-021-08

L attice sandwich structures composing of panels and lattice cores have been paid more and more attention in recent years. The lattice sandwich structures possess structural characteristics of lightweight, high specific strength and stiffness, as well as functional characteristics such as vibration and noise reduction, energy absorption and heat dissipation. Therefore, it is considered as one of the most promising new generation lightweight structures ${ }^{[1,2]}$. Among them, nickel-based superalloy lattice sandwich structures have a broad application prospect in the aerospace field due to their lightweight and high temperature resistance.

At present, research of the lattice sandwich structures are mainly focused on mechanical analysis and preparation processes. In order to obtain excellent performance, various representative unit cell structures have been

Male, born in 1963, Ph.D., Research Fellow. His research interests mainly focus on the development of advanced functional materials, design and fabrication of porous metals, and directional solidification process for superalloy turbine blade.

E-mail:Yub@chinasrif.com proposed and tested, including tetrahedral ${ }^{[3,4]}$, octahedron $^{[5,6]}$, pyramid ${ }^{[7-10]}$, and Kagome ${ }^{[11-14]}$ unit cells. Wallach et al. ${ }^{[15]}$ studied the mechanical behaviors of the metallic lattice structures with octahedral unit cell through theoretical modeling and flat compression, tension and shear experiments. The results showed that the mechanical properties such as compressive strength and shear modulus of the metallic lattice structures with octahedral unit cells were noticeably higher than the metal foam. Rathbun et al. ${ }^{[3]}$ established a theoretical model of the mechanical properties of the metallic tetrahedral lattice structures and verified with the shear and three-point bending experiments. Queheillalt et al. ${ }^{[7]}$ studied the flat compression, shear, and bending behaviors of the metallic pyramid lattice structures, established an orthotropic mechanical constitutive model, and verified the accuracy of the theoretical model by flat compression and shear tests. Hyun et al. ${ }^{[16]}$ studied the mechanical properties of the metallic Kagome and tetrahedral lattice structures under compression and shear loads by finite element numerical simulation. The results demonstrated that the mechanical properties of the Kagome structures were 
superior to the tetrahedral lattice structures and the Kagome structure showed isotropic properties under the shear load. Wang et al. ${ }^{[12]}$ prepared the metallic Kagome lattice structures using investment casting, and characterized the mechanical properties via the flat compression experiment. The results revealed that plastic buckling was the main failure mode under the flat compression load while node failure is the main failure mode under the shear load, which further confirmed that the metallic Kagome lattice structures possessed much stronger bearing ability. Consequently, lattice sandwich structures with Kagome unit cells have excellent mechanical properties compared with other lattice unit cells. However, the above studies were mainly concentrated on Al-based lattice sandwich structures, while few research studies can be found on nickel-based superalloy lattice sandwich structures with a high melting point matrix.

The preparation process is a significant factor restricting the development of the metallic lattice sandwich structures due to the complexity of lattice sandwich structures. The preparation methods of these structures mainly include investment casting ${ }^{[6,17]}$, deformation forming ${ }^{[18]}$, woven metal textiles ${ }^{[19-22]}$. Among them, the deformation forming and woven metal textiles have high requirements on the ductility of the matrix material, and the adaptability of unit cells are also limited. In contrast, the unit cell size of the metallic lattice sandwich structures manufactured by using investment casting can be as small as several millimeters, and the strut diameter can be 1-2 $\mathrm{mm}$. The main advantage of the casting method is that it can realize the design requirements of the sophisticated lattice sandwich structures. Furthermore, the high-porosity metallic lattice structures with a porosity of $80 \%-97 \%$ can be obtained by using investment casting, which can meet the engineering requirements of lightweight. Therefore, investment casting becomes one of the best processes to prepare the lattice sandwich structures. Nevertheless, the strut diameters of the lattice sandwich structures are so small and the filling path is complicated, which will result in misrun defects during the casting process. The multi-heat junction phenomenon is another technological problem during the lattice structures solidification process which easily causes casting shrinkage defects. More seriously, a higher pouring temperature and higher preheated temperature of the mold may lead to coarse grains and a decline in mechanical properties, especially in solidification of the nickel-based superalloy lattice sandwich structures. In recent years, some researchers studied the investment casting process of the lattice sandwich structures by using numerical simulation method ${ }^{[23]}$, but mainly focused on the low-melting point matrix materials, and the microstructure morphology and grain size of the lattice sandwich structures were rarely investigated.

The purpose of this work is to fabricate the nickel-based superalloy lattice sandwich structures with the Kagome unit cell using investment casting, investigating the filling and solidification behaviors during the casting process by finite element method (FEM) numerical simulation combining with experimental studies. Furthermore, the grain morphology and size of the nickel-based superalloy lattice sandwich structures were simulated using the cellular automaton-finite element method (CAFE), and validated with the experiment.

\section{Mathematical models}

\subsection{Governing equations in fluid flow and heat transfer}

(1) Mass conservation equation

$$
\frac{\partial \rho}{\partial t}+\frac{\partial(\rho u)}{\partial x}+\frac{\partial(\rho v)}{\partial y}+\frac{\partial(\rho w)}{\partial z}=0
$$

(2) Momentum conservation equation

$$
\begin{gathered}
\frac{\partial(\rho u)}{\partial t}+u \frac{\partial(\rho u)}{\partial x}+v \frac{\partial(\rho u)}{\partial y}+w \frac{\partial(\rho u)}{\partial z}=-\frac{\partial p}{\partial x}+\mu\left(\frac{\partial^{2} u}{\partial x^{2}}+\frac{\partial^{2} u}{\partial y^{2}}+\frac{\partial^{2} u}{\partial z^{2}}\right)+\rho g_{x} \\
\frac{\partial(\rho v)}{\partial t}+u \frac{\partial(\rho v)}{\partial x}+v \frac{\partial(\rho v)}{\partial y}+w \frac{\partial(\rho v)}{\partial z}=-\frac{\partial p}{\partial y}+\mu\left(\frac{\partial^{2} v}{\partial x^{2}}+\frac{\partial^{2} v}{\partial y^{2}}+\frac{\partial^{2} v}{\partial z^{2}}\right)+\rho g_{y} \\
\frac{\partial(\rho w)}{\partial t}+u \frac{\partial(\rho w)}{\partial x}+v \frac{\partial(\rho w)}{\partial y}+w \frac{\partial(\rho w)}{\partial z}=-\frac{\partial p}{\partial z}+\mu\left(\frac{\partial^{2} w}{\partial x^{2}}+\frac{\partial^{2} w}{\partial y^{2}}+\frac{\partial^{2} w}{\partial z^{2}}\right)+\rho g_{z}
\end{gathered}
$$

(3) Energy conservation equation

$$
\begin{aligned}
& \frac{\partial(\rho c T)}{\partial t}+u \frac{\partial(\rho c T)}{\partial x}+v \frac{\partial(\rho c T)}{\partial y}+w \frac{\partial(\rho c T)}{\partial z} \\
= & \frac{\partial}{\partial x}\left(\lambda \frac{\partial T}{\partial x}\right)+\frac{\partial}{\partial y}\left(\lambda \frac{\partial T}{\partial y}\right)+\frac{\partial}{\partial z}\left(\lambda \frac{\partial T}{\partial z}\right)+Q
\end{aligned}
$$

where $u, v$, and $w$ are velocity components in the $x, y$, and $z$ directions, $t$ is time, $g_{x}, g_{y}$, $g_{z}$ are the acceleration of gravities in $x, y, z$ directions, $\rho$ is the density, $\mu$ is viscosity, $\lambda$ is the thermal conductivity, $c$ is the specific heat capacity, $T$ is the node temperature and $Q$ is heat source.

\subsection{Mathematical model of CAFE}

\subsubsection{Nucleation model}

The heterogeneous nucleation in the microscopic simulation process includes two forms: instantaneous nucleation and continuous nucleation. The CAFE method uses a continuous nucleation model to deal with the nucleation process, assuming that the nucleation occurs at a series of possible nucleation sites in the bulk volume and at the surface of the mold. The Gaussian distribution function is used to describe the variation of the grain density ${ }^{[24,25]}$, which can be expressed as follows: 


$$
\frac{d n}{d(\Delta T)}=\frac{n_{\max }}{\sqrt{2 \pi} \Delta T_{\sigma}} \exp \left[-\frac{\left(\Delta T-\Delta T_{n}\right)^{2}}{2 \Delta T_{\sigma}^{2}}\right]
$$

where $n$ is the grain density, $n_{\max }$ is the maximum nucleation density, $n_{\max , \mathrm{v}}$ is the volume nucleation density, $n_{\max , \mathrm{s}}$ is the surface nucleation density, $\Delta T$ is total undercooling, $\Delta T_{\mathrm{n}}$ is the mean undercooling, $\Delta T_{\sigma}$ is the standard deviation of the mean undercooling. When the mean undercooling is given, the density of the nucleus can be obtained by Eq. (5):

$$
n(\Delta T)=\int_{0}^{\Delta T} \frac{d n}{d(\Delta T)} d(\Delta T)
$$

\subsubsection{Grain growth model}

During the solidification of the alloy, the growth of the dendritic tip is mainly dominated by the undercooling, and the total undercooling can be expressed by Eq. (6):

$$
\Delta T=\Delta T_{\mathrm{c}}+\Delta T_{\mathrm{t}}+\Delta T_{\mathrm{r}}+\Delta T_{\mathrm{k}}
$$

where $\Delta T_{\mathrm{c}}, \Delta T_{\mathrm{t}}, \Delta T_{\mathrm{r}}$ and $\Delta T_{\mathrm{k}}$ are the solute diffusion undercooling, thermal diffusion undercooling, curvature undercooling and attachment kinetics undercooling, respectively. For most metallic alloys, the last three contributions are small and can be ignored in the calculation. The growth rate of the equiaxed and columnar morphologies can be described by the KGT model ${ }^{[26,27]}$ :

$$
v=a_{2} \Delta T^{2}+a_{3} \Delta T^{3}
$$

where, $a_{2}$ and $a_{3}$ are the growth kinetic coefficients.

\subsection{FE and CA model coupling}

The interpolation factor between the FE node and the CA cell is defined in the CAFE model, and the influence of the latent heat is introduced to ensure that the microstructure is the function of the temperature field. The cell of CA and the finite element nodes $i, j$, and $k$ each have non-zero interpolation factors. These factors, combined with the temperature of the FE node, can determine the temperature of the cells in the grid. The latent heat released by the dendrite nucleation and growth is summed and the node temperature is updated ${ }^{[28]}$.

\section{Simulation model description}

The gating and wedge feeding system (the panel part with varied thicknesses) for the Kagome lattice sandwich structures were designed, and the geometric model of Kagome lattice sandwich structure was established by Solidworks software. The strut diameter of the Kagome unit is $4 \mathrm{~mm}$, the height of the lattice core is $23.5 \mathrm{~mm}$, the thickness of the panel is $3 \mathrm{~mm}$, the angle of the varied panel is $7^{\circ}$ and the overall dimension of the Kagome lattice sandwich structure is $210 \times 120 \times 29.5(\mathrm{~mm})$. The element size of the Kagome lattice structure is $1 \mathrm{~mm}$, and the element size of the gating and wedge feeding system with varied panel thicknesses is $5 \mathrm{~mm}$. The $2 \mathrm{D}$ elements quantity is about
374 thousand and 3D elements quantity is about 9 million. The geometric model and the FEM mesh generated by ProCAST software are shown in Fig. 1.

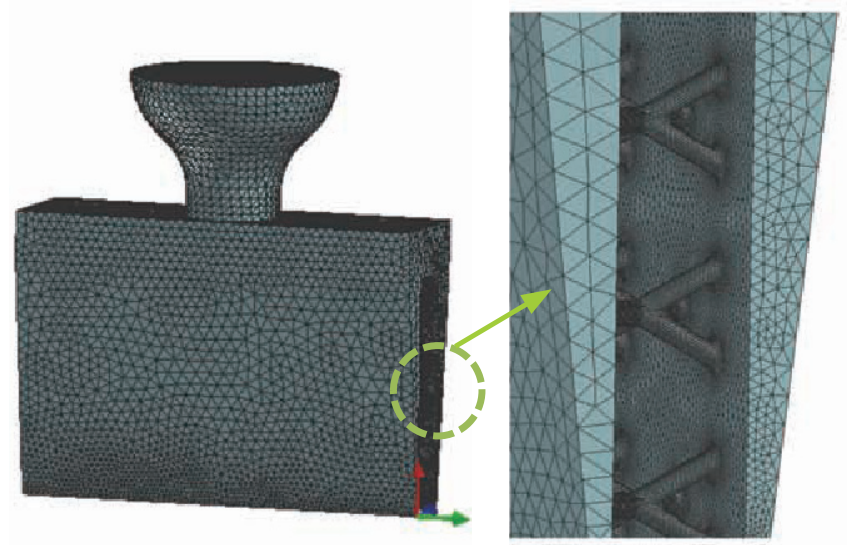

Fig. 1: Finite element mesh of Kagome lattice sandwich $\square\left[\begin{array}{ll}\square \square \\ \square \square\end{array}\right.$

The test alloy is Inconel 713 superalloy, and its thermophysical parameters were based on ProCAST software. Some of the initial and boundary conditions are listed in Table 1.

Table 1: Thermo-physical parameters, initial and boundary conditions

\begin{tabular}{cc} 
Calculated parameters & Value \\
\hline Solidus temperature & $1,209^{\circ} \mathrm{C}$ \\
Liquidus temperature & $1,342{ }^{\circ} \mathrm{C}$ \\
Shell material & Refractory alumina \\
Pouring temperature & $1,442{ }^{\circ} \mathrm{C}$ \\
Pouring velocity & $0.5 \mathrm{~m} / \mathrm{s}$ \\
Mold preheated temperature & $1,000{ }^{\circ} \mathrm{C}$ \\
Interface heat transfer coefficient & $1,000 \mathrm{~W} /\left(\mathrm{m}^{2} \cdot \mathrm{K}\right)$ \\
Emissivity coefficient of the enclosure & 0.92 \\
Ambient temperature & $80{ }^{\circ} \mathrm{C}$
\end{tabular}

After the flow and heat transfer calculations were accomplished, the grain morphology and size of the Kagome lattice structures were calculated using the CAFE method, and the cell size was $100 \mu \mathrm{m}$ with the same FEM mesh. In the CAFE method, the surface nucleation density $n_{\text {max,s }}$, the volume nucleation density $n_{\text {max, }}$ and the volume nucleation mean undercooling $\Delta T_{\mathrm{n} . \mathrm{v}}$ were the most important parameters to simulate the grain nucleation and growth ${ }^{[29]}$. According to the calculation method recommended by the ASTM standard ${ }^{[30]}$, the $n_{\text {max }, \mathrm{v}}=0.8 n_{\text {max }, \mathrm{S}}{ }^{3 / 2}$, and the $n_{\text {max }, \mathrm{S}}$ were obtained by the experimental statistics. In this work, the surface nucleation density $n_{\max , \mathrm{s}}=3.98 \times 10^{6} \mathrm{~m}^{-2}$ according to the statistics of the experimental results, giving the volume nucleation density $n_{\text {max,v }}=6.35 \times 10^{9} \mathrm{~m}^{-3}$ from the above formula calculation. The surface nucleation mean undercooling $\Delta T_{\mathrm{n} . \mathrm{s}}=1 \mathrm{~K}^{[29]}$, the standard deviation of the surface necleation mean undercooling $\Delta T_{\sigma . \mathrm{s}}=0.1$ $\mathrm{K}^{[29]}$. The volume nucleation mean undercooling $\Delta T_{\mathrm{n} . \mathrm{v}}=3 \mathrm{~K}$ based on the experimental results, and the standard deviation of the 
volume necleation mean undercooling $\Delta T_{\sigma . \mathrm{v}}=1 \mathrm{~K}^{[29]}$.

In this work, pseudo-binary alloy phase diagrams were applied to deal with Inconel 713 superalloy. The composition $C_{\text {o, }}$, partition coefficient $k$, liquidus slope $m$, and solute diffusion coefficient $D_{1}$ of Ni-X Alloy are listed in Table 2. The growth kinetic coefficients of Inconel 713 were calculated based on Table 2 by using ProCAST software and $a_{2}=0, a_{3}=2.062 \times 10^{-7}$.

Table 2: Composition, liquidus slope, partition coefficient, and solute diffusion coefficient of $\mathrm{Ni}-\mathrm{X}$ alloy

$\begin{array}{ccccc}\text { Element } & C_{0}(w t . \%) & m(K) & k & D_{1}\left(\mathrm{~m}^{2} / \mathbf{s}\right) \\ \mathrm{Al} & 6 & -13.8 & 0.90 & 3 \times 10^{-9} \\ \mathrm{C} & 0.13 & -48.3 & 0.26 & 3 \times 10^{-9} \\ \mathrm{Co} & 0.15 & -0.32 & 1.12 & 3 \times 10^{-9} \\ \mathrm{Cr} & 13.9 & -3.91 & 0.99 & 3 \times 10^{-9} \\ \mathrm{Fe} & 0.2 & -4.58 & 0.88 & 3 \times 10^{-9} \\ \mathrm{Mo} & 4 & -3.84 & 0.84 & 3 \times 10^{-9} \\ \mathrm{Nb} & 2 & -8.87 & 0.54 & 3 \times 10^{-9} \\ \mathrm{Ti} & 0.9 & -13.74 & 0.67 & 3 \times 10^{-9}\end{array}$

\section{Materials and experiment method}

\subsection{Matrix material}

Inconel 713 superalloy is a $\gamma^{\prime}$ phase precipitation reinforced nickel-based superalloy. Its good creep strength, high thermal fatigue resistance and oxidation resistance below $900{ }^{\circ} \mathrm{C}$ ensure that the nickel-based superalloy lattice sandwich structures are suitable for complex high temperature conditions. Therefore, this work selected Inconel 713 as the matrix material of the lattice sandwich structures. The chemical composition of the Inconel 713 is shown in Table 3.

\subsection{Fabrication of nickel-based superalloy lattice sandwich structures}

The HRPS-V rapid prototyping system manufactured by Wuhan Binhu Mechanical \& Electrical Co., Ltd. was used to prepare the precursor of the Kagome lattice sandwich structures [Fig. 2(a)] via selective laser sintering. The material of the precursor was polystyrene powder with a particle size of about $100 \mu \mathrm{m}$. The ceramic shell mold was used for the investment casting of the lattice sandwich structures.

A $50 \mathrm{~kg}$ semi-continuous vacuum melting and casting furnace was used to implement the vacuum casting process. After the ceramic mold was removed with chemical etchant, the gating and wedge feeding system were cut off by using wire-electrode cutting. The prepared nickel-based superalloy Kagome lattice sandwich structure sample is shown in Fig. 2(b).

Table 3: Chemical compositions of Inconel 713 (wt.\%)

\begin{tabular}{cccccccc} 
C & Cr & Mo & Al & Ti & Fe & Nb & B \\
\hline $0.08-0.16$ & $11.5-13.5$ & $3.8-4.8$ & $5.5-6.4$ & $0.5-1.0$ & $\leqslant 1.0$ & $1.8-2.5$ & $0.008-0.020$ \\
$\mathrm{Zr}$ & $\mathrm{Mn}$ & $\mathrm{Si}$ & $\mathrm{P}$ & $\mathrm{S}$ & $\mathrm{Pb}$ & $\mathrm{Bi}$ & $\mathrm{Ni}$ \\
$0.06-0.15$ & $\leqslant 0.5$ & $\leqslant 0.5$ & $\leqslant 0.015$ & $\leqslant 0.01$ & $\leqslant 0.001$ & $\leqslant 0.0001$ & $\mathrm{Bal}$
\end{tabular}

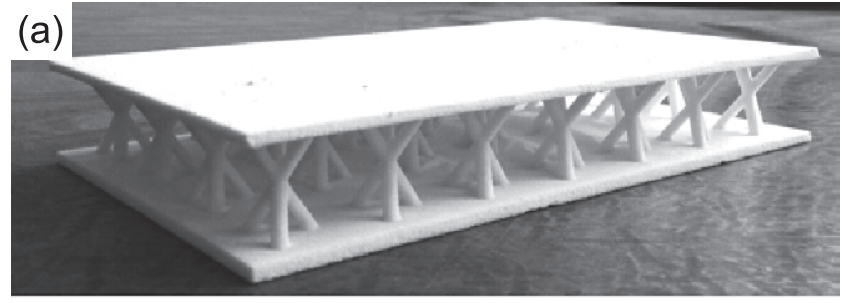

(b)

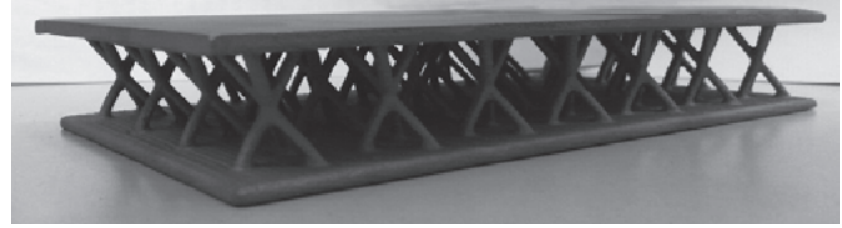

Fig. 2: (a) Precursor by selective laser sintering; (b) Sample of nickel-based superalloy Kagome lattice sandwich structure by investment casting process

\section{Results and discussion}

\subsection{Mould filling analysis}

The lattice sandwich structures have small strut diameters and complicated filling path, and casting defects such as misrun and oxidation inclusions easily occur. It is necessary to design the gating and feeding system to ensure that the filling resistance is low and to keep the filling stable, so as to obtain high-quality completed lattice sandwich structures. The numerical simulation results of the filling process of the Kagome lattice sandwich structure can be seen in Fig. 3. After pouring, it flowed relatively symmetrically into the bottom of the lattice sandwich structure, as shown in Fig. 3 (a). The first layer of the lattice core was filled at $0.34 \mathrm{~s}$, and the filling was stable and smooth. The simulated and the experimental results show that the lattice sandwich structures did not suffer from the misrun during the filling process, which ensured the integrity of the lattice sandwich structure. At the same time, the upper lattice core body can be used as a gas vent to ensure that no air entrapment occurs during filling. 
(a)

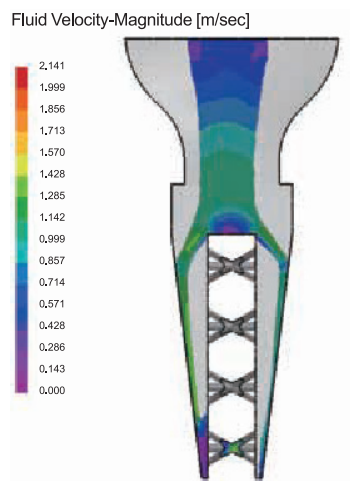

(d)

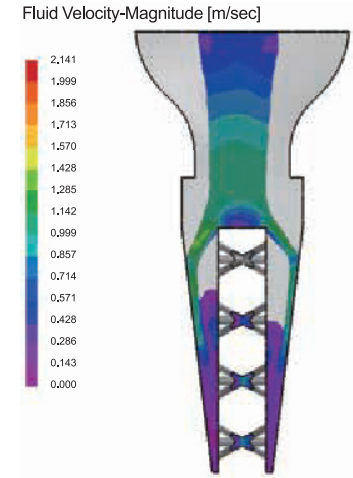

(b)

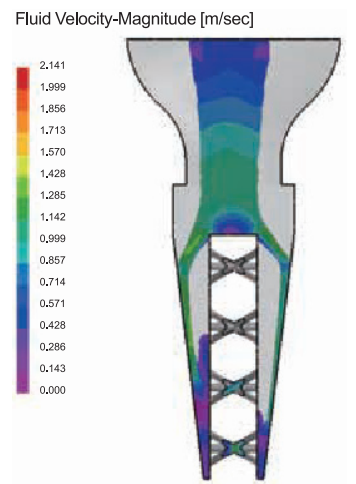

(e)

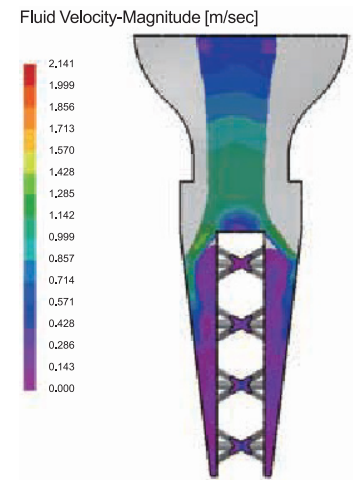

(c)

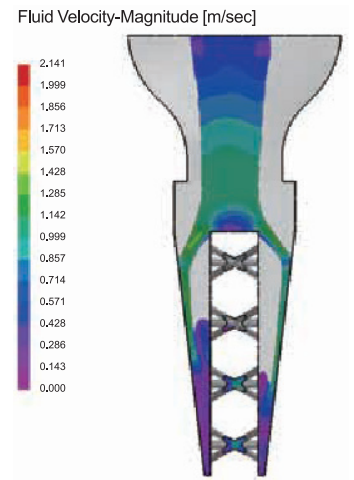

(f)

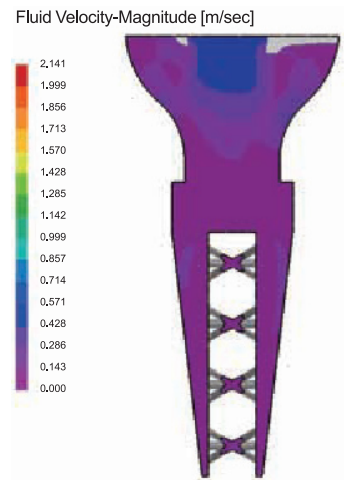

Fig. 3: Filling process of Kagome lattice sandwich structure: (a) $0.34 \mathrm{~s}$; (b) $0.50 \mathrm{~s}$; (c) $0.70 \mathrm{~s}$; (d) $0.94 \mathrm{~s}$; (e) $1.24 \mathrm{~s}$; (f) $2.33 \mathrm{~s}$

\subsection{Solidification analysis}

Figure 4 shows the solidification process of the Kagome lattice sandwich structure, and Fig. 5 shows the cooling curves of the selected positions in the lattice core and panel. It can be seen from Figs. 4 (a) and (b) that when the higher temperature melt met the lower temperature shell wall, it was rapidly cooled, and the core of the lattice sandwich structure solidified almost at the same time due to its small pore diameters, so (a)

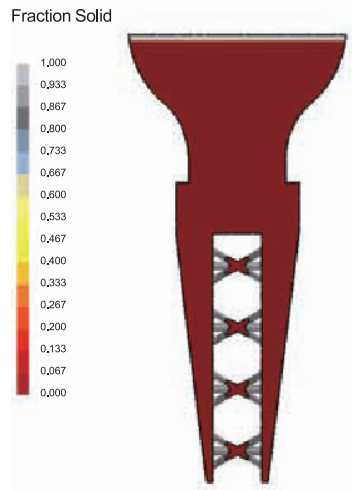

(d)

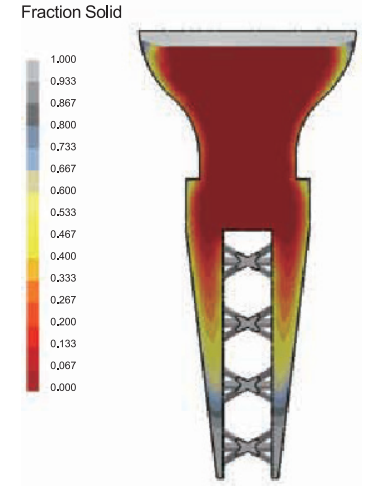

(b)

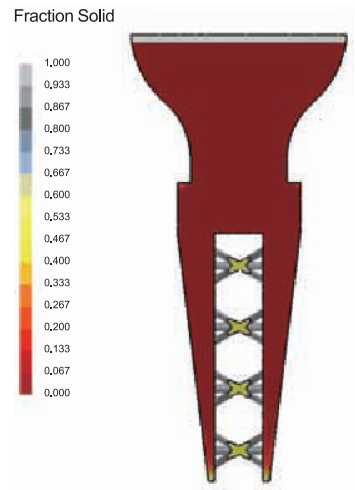

(e)

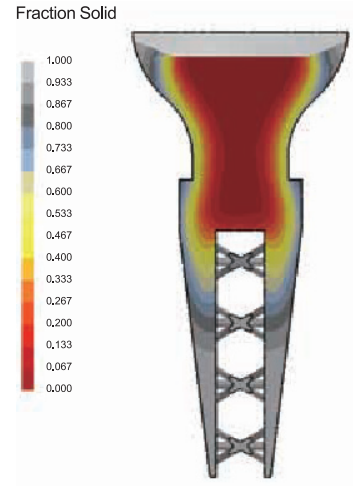

(c)

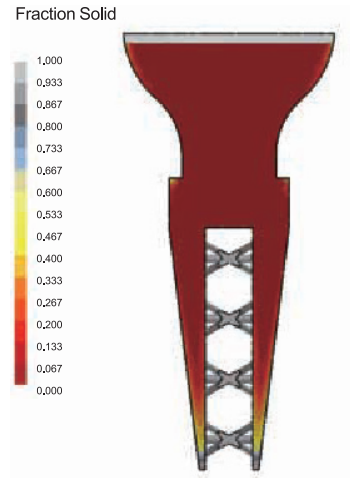

(f)

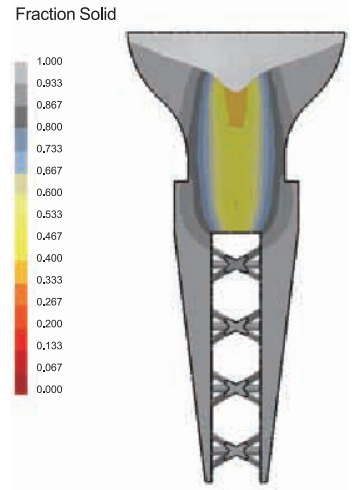

Fig. 4: Solidification process of the Kagome lattice sandwich structure: (a) $2.40 \mathrm{~s}$; (b) $10.09 \mathrm{~s}$; (c) $19.82 \mathrm{~s}$; (d) $49.82 \mathrm{~s}$; (e) $109.82 \mathrm{~s}$; (f) $259.82 \mathrm{~s}$ 

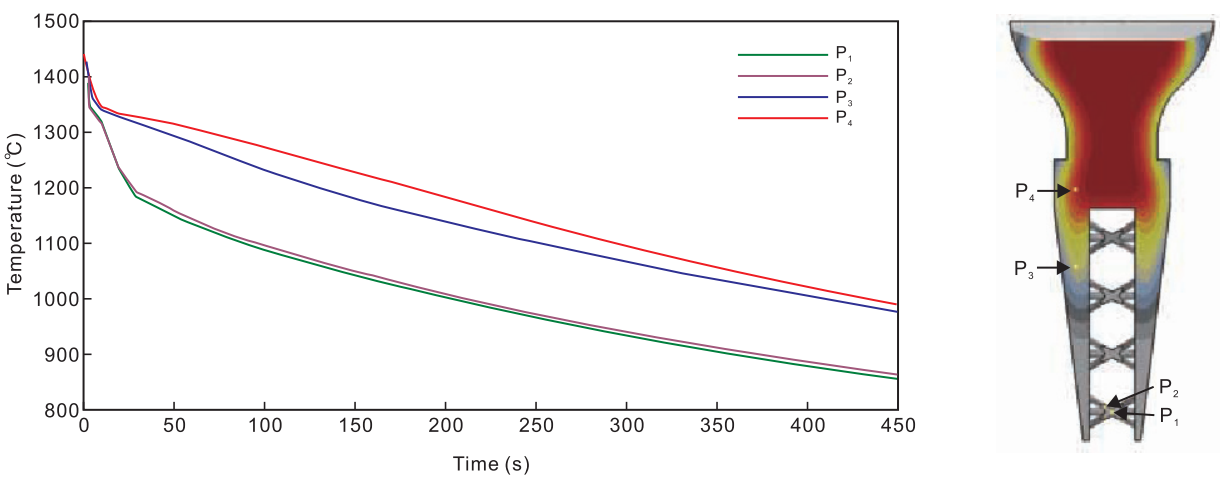

Fig. 5: Cooling curves (a) for different positions of the core and panel (b)

the solidification style of the lattice core was a simultaneous solidification. Meanwhile, the corresponding panel structure had an external wedge feeding channel, so the panel structure solidified sequentially, as shown in Fig. 4(c)-(f).

From the cooling curves of the core and the panel, it can be seen that the cooling curve firstly drops, and then due to the existence of latent heat, a small platform appears, but the $\mathrm{P}_{1}$ and $\mathrm{P}_{2}$ positions did not have a platform due to the large temperature gradient and fast solidification rate. Furthermore, the cooling curves of the lattice core $\left(\mathrm{P}_{1}\right.$ and $\left.\mathrm{P}_{2}\right)$ are lower than that of the panel $\left(\mathrm{P}_{3}\right.$ and $\left.\mathrm{P}_{4}\right)$, and the downward trend is more obvious due to the very small size of the core with the more intense cooling conditions. This also explains why the lattice core solidified simultaneously.

\subsection{Microstructure morphology and grain size analysis}

Figure 6 shows the numerical simulation results of the grain morphology of the Kagome lattice sandwich structure using the CAFE method. Figure 7 shows the comparison of the simulated and experimentally observed solidification grain morphology and size of the Kagome lattice sandwich structure at Position $P_{1}$. Figure 8 shows the optical microscope image of the strut crosssection at Position $\mathrm{P}_{1}$.
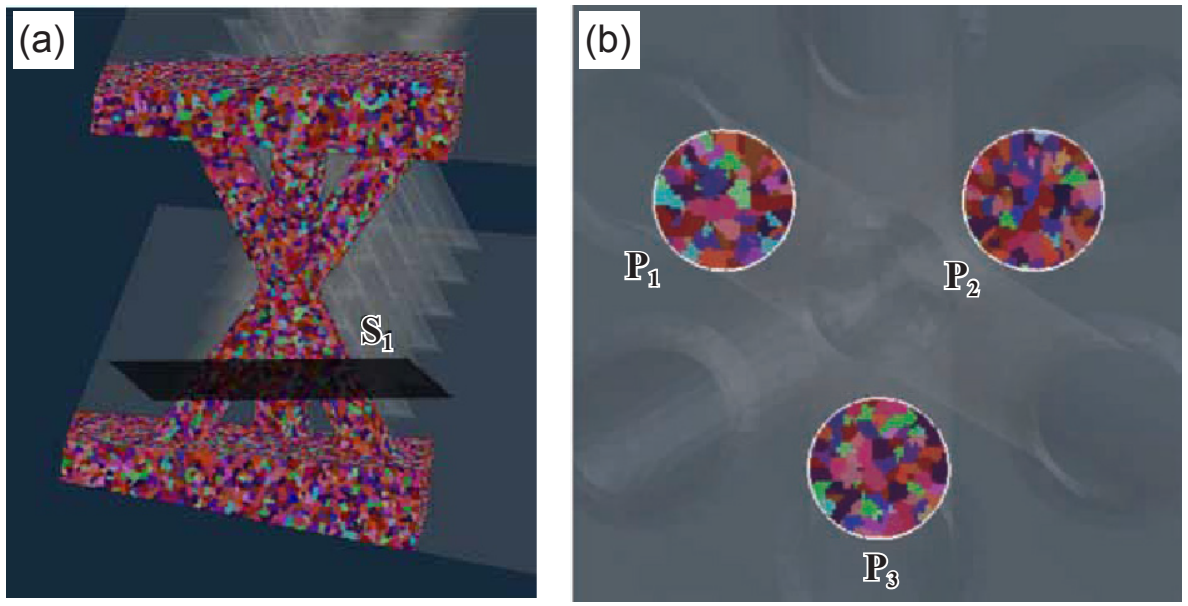

Fig. 6: Simulated solidification grain structures of the Kagome lattice sandwich structure (a) and grain structure at $\mathrm{S}$ cross-section (b)
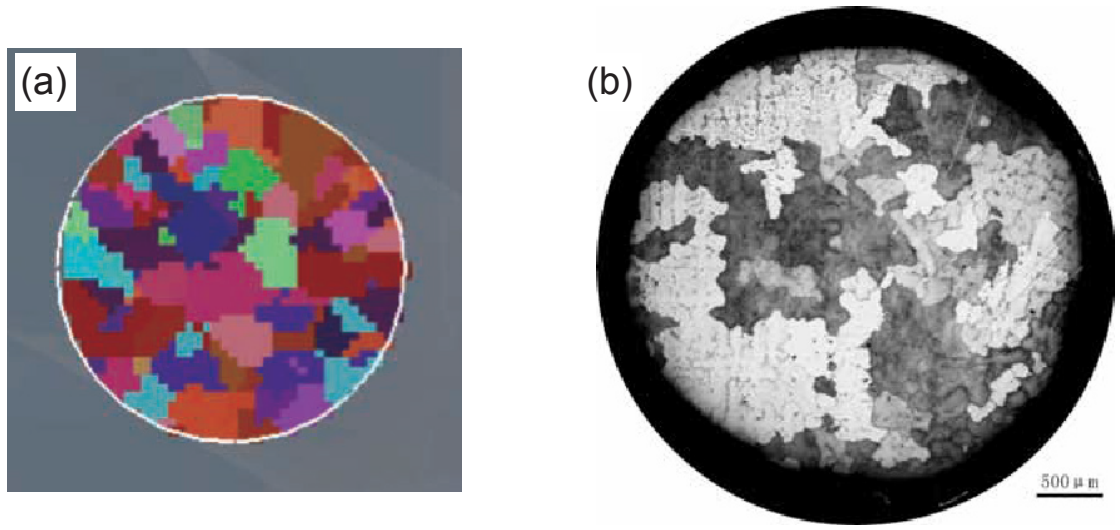

Fig. 7: Comparison of the simulated (a) and experimentally observed (b) solidification grain structures of the Kagome lattice sandwich structure at $P_{\square}$ 

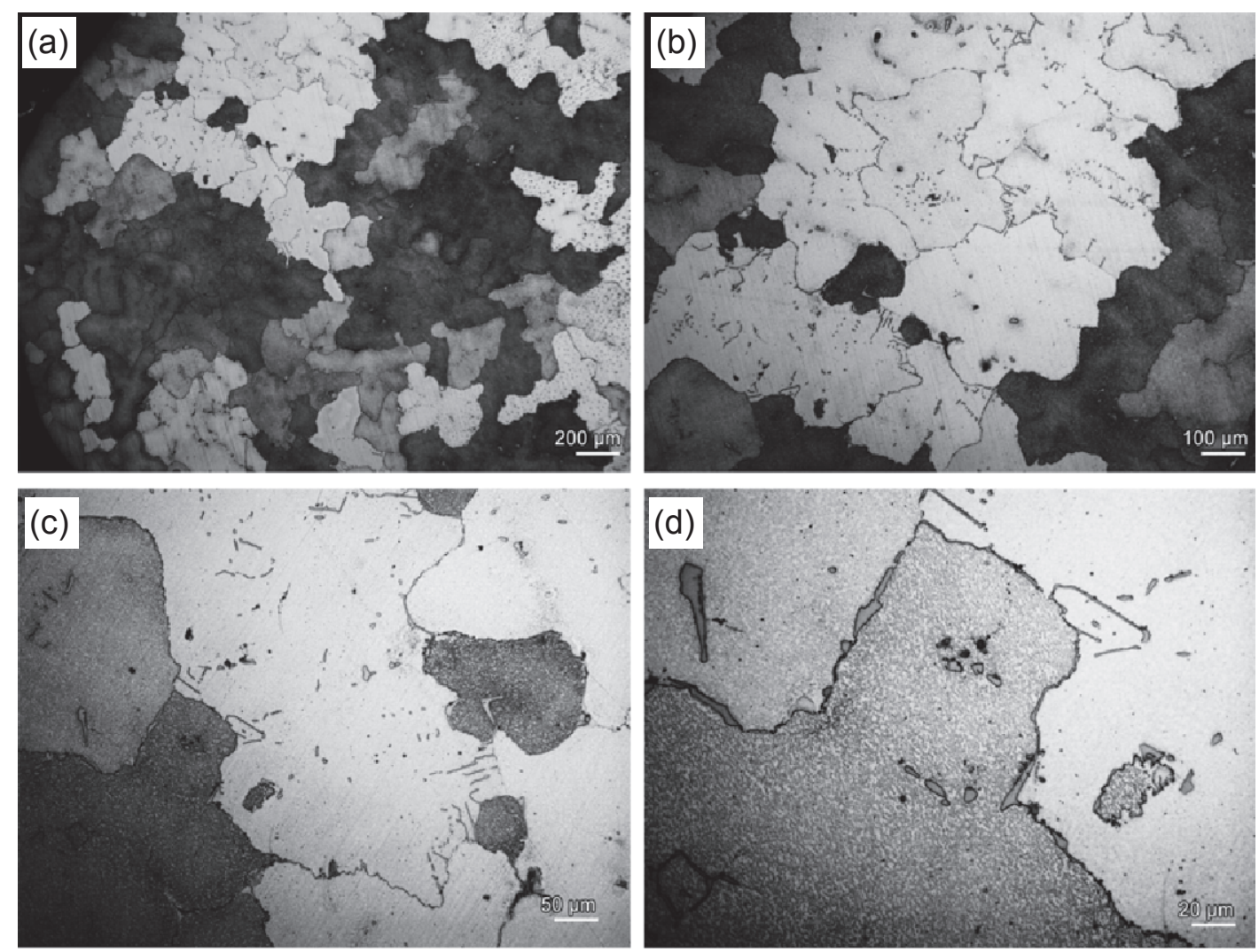

Fig. 8: Optical microscope image of the strut cross-section at $P_{\square}$

Both the simulated and experimental results in Fig. 7 show the equaxied grain morphology, the simulated mean diameter of grains is about $539.56 \mu \mathrm{m}$, and that of the experimental grains is about $507.79 \mu \mathrm{m}$. The simulated grain morphology and sizes of the microstructure are consistent with the results of optical microscope images, indicating that the nucleation parameters and growth kinetic coefficients of the CAFE method can be applied to the numerical simulation of the solidification grain morphology and size of the nickel-based superalloy Kagome lattice sandwich structures.

Using the above calculation method, different process parameters such as the superheat of melting and mold preheated temperature were implemented to study the change trend of the grain size. Different superheat of $50{ }^{\circ} \mathrm{C}, 100{ }^{\circ} \mathrm{C}, 150{ }^{\circ} \mathrm{C}$ and different mold preheated temperatures of $900{ }^{\circ} \mathrm{C}, 1000{ }^{\circ} \mathrm{C}, 1050$ ${ }^{\circ} \mathrm{C}$ were used to simulate the grain size of the Kagome lattice sandwich structures, and the results are shown in Table 4.

The simulated results show that the superheat of melting and mold preheated temperatures have significant influence on the grain sizes. With the increase of the superheat of melting and

Table 4: Grain sizes of Kagome lattice sandwich structures with different process parameters

\begin{tabular}{ccccc}
$\begin{array}{c}\text { Mold preheated } \\
\text { temperature }\end{array}$ & \multicolumn{3}{c}{ Melting superheat } \\
\hline $900^{\circ} \mathrm{C}$ & ${ }^{\circ} \mathrm{C}$ & $419.70 \mu \mathrm{C}$ & $\mathbf{1 5 0}{ }^{\circ} \mathrm{C}$ \\
$1000^{\circ} \mathrm{C}$ & $465.12 \mu \mathrm{m}$ & $539.56 \mu \mathrm{m}$ & $632.34 \mu \mathrm{m}$ \\
$1050^{\circ} \mathrm{C}$ & $487.34 \mu \mathrm{m}$ & $558.98 \mu \mathrm{m}$ & $651.10 \mu \mathrm{m}$ \\
\hline
\end{tabular}

mold preheated temperatures, the grains of the Kagome lattice sandwich structures become coarser. The main reason is that the higher superheat of melting decreases the volume nucleation density and some nucleation sites disappeared due to the high temperatures. The study also confirmed that with the increase of the superheat of melting, the undercooling of the nucleation decreased according to Eqs. (4) and (5), and the volume nucleation density decreased subsequently. The higher mold preheated temperatures also caused the decreasing of the surface nucleation density and undercooling, and the grain sizes of the Kagome lattice sandwich structures became great. Therefore, lower superheat of melting and mold preheated temperatures are recommended in order to obtain the fine grain while assuring the integrity of the Kagome lattice sandwich structures for industrial application.

\section{Conclusions}

In this work, the Kagome lattice unit was adopted to design the lattice sandwich structures and the nickel-based superalloy lattice sandwich structures were prepared by indirect additive manufacturing combined with the investment casting process. The grain morphology and sizes were simulated by using the CAFE method. The following conclusions can be drawn:

(1) The flow calculation results using ProCAST software show that the mould filling is stable. The temperature field shows that the lattice core part mainly solidifies simultaneously, while the panel part solidifies in sequence.

(2) The relatively accurate simulated parameters and boundary conditions are obtained to calculate the grain size of the 
Kagome lattice sandwich structures with the CAFE numerical simulation method. The average grain size is about $500 \mu \mathrm{m}$, and the grains are mainly equiaxed according to the simulated and experimental results.

(3) The simulated results show that the superheat of melting and the mold preheated temperature have significant influence on the grain sizes of the Kagome lattice sandwich structures, lower superheat of melting and mold preheated temperatures are encouraged to obtain the fine grains while assuring the integrity of the Kagome lattice sandwich structures for industrial application.

\section{Acknowledgements}

This work was financially supported by the National Science and Technology Major Project of China (No. 2017ZA04014001), the Natural Science Foundation of Liaoning Province of China (Nos. 2019-ZD-0997, 20170540890) and the Technology Development Fund of China Academy of Machinery Science and Technology (No. 170217ZS01).

\section{References}

[1] Evans A G, Hutchinson J W, Fleck N A, et al. The topological design of multifunctional cellular metals. Progress in Materials Science, 2001, 46(3/4): 309-327.

[2] Deshpande V S, Ashby M F and Fleck N A. Foam topology: Bending versus stretching dominated architectures. Acta Materialia, 2001, 49(6): 1035-1040.

[3] Rathbun H J, Wei Z, He M Y, et al. Measurement and simulation of the performance of a lightweight metallic sandwich structure with a tetrahedral truss core. Journal of Applied Mechanics, 2004, 71(3): 368

[4] Lim J H, Kang K J. Mechanical behavior of sandwich panels with tetrahedral and kagome truss cores fabricated from wires. International Journal of Solids and Structures, 2006, 43(17): 5228-5246.

[5] Dong L, Wadley H. Shear response of carbon fiber composite octet-truss lattice structures. Composites Part A: Applied Science and Manufacturing, 2016, 81: 182-192.

[6] Deshpande V S, Fleck N A, Ashby M F. Effective properties of the octet-truss lattice material. Journal of the Mechanics and Physics of Solids, 2001, 49: 1747-1769.

[7] Queheillalt D T, Murty Y, Wadley H N G. Mechanical properties of an extruded pyramidal lattice truss sandwich structure. Scripta Materialia, 2008, 58(1): 76-79.

[8] Sun Y, Gao L. Mechanical behavior of all-composite pyramidal truss cores sandwich panels. Mechanics of Materials, 2013, 65: $56-65$.

[9] Wang B, Wu L, Ma L, et al. Mechanical behavior of the sandwich structures with carbon fiber-reinforced pyramidal lattice truss core. Materials \& Design, 2010, 31(5): 2659-2663.

[10] Zok F W, Waltner S A, Wei Z, et al. A protocol for characterizing the structural performance of metallic sandwich panels: Application to pyramidal truss cores. International Journal of Solids and Structures, 2004, 41(22-23): 6249-6271.

[11] Lee B K, Kang K J. A parametric study on compressive characteristics of wire-woven bulk kagome truss cores. Composite Structures, 2010, 92(2): 445-453.
[12] Wang J, Evans A G, Dharmasena K, et al. On the performance of truss panels with kagomé cores. International Journal of Solids and Structures, 2003, 40(25): 6981-6988.

[13] Ullah I, Elambasseril J, Brandt M, et al. Performance of bioinspired kagome truss core structures under compression and shear loading. Composite Structures, 2014, 118: 294-302.

[14] Fan H L, Meng F H, Yang W. Sandwich panels with kagome lattice cores reinforced by carbon fibers. Composite Structures, 2007, 81(4): 533-539.

[15] Wallach J C, Gibson L J. Mechanical behavior of a threedimensional truss material. International Journal of Solids and Structures, 2001, 38(40-41): 7181-7196.

[16] Hyun S, Karlsson A M, Torquato S, et al. Simulated properties of kagomé and tetragonal truss core panels. International Journal of Solids and Structures, 2003, 40(25): 6989-6998.

[17] Kroupová I, Bednářová V, Elbel T, et al. Proposal of method of removal of mould material from the fine structure of metallic foams used as filters. Archives of Metallurgy and Materials 2014, 59(2): 727-730.

[18] Wadleya H N G, Fleckb N A, Evansc A G. Fabrication and structural performance of periodic cellular metal sandwich structures. Composites Science and Technology, 2003, 63(16): 2331-2343.

[19] Lee Y H, Kang K J. A wire-woven cellular metal: Part-i, optimal design for applications as sandwich core. Materials \& Design, 2009, 30(10): 4434-4443.

[20] Kang K J. Wire-woven cellular metals: The present and future. Progress in Materials Science, 2015, 69: 213-307.

[21] Lee M G, Yoon J W, Han S M, et al. Bending response of sandwich panels with discontinuous wire-woven metal cores. Materials \& Design, 2014, 55: 707-717.

[22] Lee M G, Yoon J W, Han S M, et al. In-plane compression response of wire-woven metal cored sandwich panels. Materials \& Design, 2014, 55: 718-726.

[23] Dong D, Zhu D D, He Q, et al. Numerial simulation of A356 truss core panels by low pressure investment casting. Special-Casting and Non-ferrous Alloys, 2016, 36(11): 1175-1177. (In Chinese)

[24] Rappaz M, Gandin C A. Probabilistic modelling of microstructure formation in solidification processes. Acta Metallurgica et Materialia, 1993, 41(2): 345-360.

[25] Thévoz P, Desbiolles J L, Rappaz M. Modeling of equiaxed microstructure formation in casting. Metallurgical Transactions A, 1989, 20(2): 311-322.

[26] Lipton J, Glicksman M E, Kurz W. Dendritic growth into undercooled alloy metals. Materials Science and Engineering, 1984, 65(1): 57-63.

[27] Kurz W, Giovanola B, Trivedi R. Theory of microstructural development during rapid solidification. Acta Metallurgica, 1986, 34(5): 823-830.

[28] Gandin C A, Rappaz M. A coupled finite element-cellular automaton model for the prediction of dendritic grain structures in solidification processes. Acta Metallurgica et Materialia, 1994 42(7): 2233-2246.

[29] Seo S M, Kim I S, Jo C Y, et al. Grain structure prediction of $\mathrm{Ni}$-base superalloy castings using the cellular automaton-finite element method. Materials Science and Engineering: A, 2007, 449-451: 713-716.

[30] Song W, Zhang J M, Liu Y, et al. Numerical simulation of solidification structure of $6.5 \mathrm{wt} . \%$ si steel ingot slab. Ironmaking \& Steelmaking, 2015, 42(9): 656-663. 